\title{
PERBANDINGAN GUGUS FUNGSI DAN MORFOLOGI PERMUKAAN KARBON AKTIF DARI PELEPAH KELAPA SAWIT MENGGUNAKAN AKTIVATOR ASAM FOSFAT $\left(\mathrm{H}_{3} \mathrm{PO}_{4}\right)$ DAN ASAM NITRAT $\left(\mathrm{HNO}_{3}\right)$
}

\author{
THE COMPARISON OF FUNCTION GROUP AND SURFACE MORPHOLOGY OF \\ ACTIVATED CARBON FROM OIL PALM FROND USING PHOSPORIC ACID $\left(\mathrm{H}_{3} \mathrm{PO}_{4}\right)$ \\ AND NITRIC ACID $\left(\mathrm{HNO}_{3}\right)$ AS AN ACTIVATOR
}

\author{
Vidyanova Anggun Mentari", Gewa Handika, Seri Maulina \\ Departemen Teknik Kimia, Fakultas Teknik, Universitas Sumatera Utara, \\ Jl. Almamater Kampus USU Medan 20155, Indonesia \\ "Email : vidyanovaanggunmentari@gmail.com
}

\begin{abstract}
Abstrak
Indonesia termasuk negara produsen kelapa sawit terbesar di dunia. Berdasarkan laporan Badan Pusat Statistik luas perkebunan kelapa sawit di Indonesia pada tahun 2016 sebesar 11.672.861 Ha. Limbah perkebunan kelapa sawit tersedia dalam jumlah yang banyak dan belum dimanfaatkan secara optimal, salah satunya yaitu pelepah kelapa sawit. Pelepah kelapa sawit termasuk kategori limbah basah (wet by-products) dengan jumlah produksi pelepah kelapa sawit pada tahun 2016 yaitu sebesar 19.143 .492 ton. Penelitian ini membahas perbandingan gugus fungsi dan morfologi permukaan karbon aktif dari pelepah kelapa sawit dengan aktivator $\mathrm{H}_{3} \mathrm{PO}_{4}$ dan $\mathrm{HNO}_{3}$. Penelitian ini bertujuan untuk mengetahui perbandingan gugus fungsi dan morfologi permukaan karbon aktif dari pelepah kelapa sawit dengan aktivator $\mathrm{H}_{3} \mathrm{PO}_{4}$ dan $\mathrm{HNO}_{3}$. Metode yang dilakukan meliputi proses impregnasi, karbonisasi, dan pencucian. Konsentrasi aktivator yang digunakan yaitu $20 \%$ dengan suhu aktivasi $400{ }^{\circ} \mathrm{C}$. Analisa yang dilakukan pada penelitian ini meliputi analisis morfologi permukaan karbon aktif dengan menggunakan SEM dan analisis spektra secara FTIR terhadap karbon aktif. Hasil analisa morfologi menggunakan SEM menunjukkan adanya pori yang terbentuk pada karbon aktif dan identifikasi dengan spektrofotometer FTIR menunjukkan bahwa karbon aktif pada penelitian ini mengandung gugus fungsi $\mathrm{C}=\mathrm{O}, \mathrm{C}=\mathrm{C}, \mathrm{C}-\mathrm{C}, \mathrm{N}=\mathrm{O}, \mathrm{C}-\mathrm{N}, \mathrm{C}-\mathrm{OH}, \mathrm{CH}_{2}$ dan $\mathrm{C}-\mathrm{H}$.
\end{abstract}

Kata kunci : karbon aktif, pelepah kelapa sawit, karbonisasi, asam fosfat, asam nitrat

\begin{abstract}
Indonesia is one of the biggest producent of palm oil in the world. According to Badan Pusat Statistik (Central Bureau of Statistics), on 2016 wide of the palm oil estate in Indonesia is $11.672 .861 \mathrm{Ha}$. The waste of palm oil plantations so many and isn't used optimal, for the example is oil palm frond. Oil palm frond is one of the wet of waste with the number of production as much as 19.143.492 ton on 2016. This research will discuss the comparison of functional group and surface morphology activated carbon of oil palm frond with use $\mathrm{H}_{3} \mathrm{PO}_{4}$ and $\mathrm{HNO}_{3}$ as an activator. This research purpose to know the comparison of functional group and surface morphology activated carbon of oil palm frond with use $\mathrm{H}_{3} \mathrm{PO}_{4}$ and $\mathrm{HNO}_{3}$ as an activator. The method includes impregnation, carbonization, and washing process. The concentration of activator is $20 \%$ with $400{ }^{\circ} \mathrm{C}$ activation temperature. This research is used morphology surface activated carbon analysis with SEM and FTIR spectrophotometer. The result of analysis with SEM show there is pore formed on activated carbon and the indentification with spechtrophotometer FTIR shows that activated carbon is contain of functional group are $\mathrm{C}=\mathrm{O}, \mathrm{C}=\mathrm{C}, \mathrm{C}$ $\mathrm{C}, \mathrm{N}=\mathrm{O}, \mathrm{C}-\mathrm{N}, \mathrm{C}-\mathrm{OH}, \mathrm{CH}_{2}$ and $\mathrm{C}-\mathrm{H}$.
\end{abstract}

Keywords : activated carbon, oil palm frond, carbonization, phospate acid, nitric acid.

\section{Pendahuluan}

Pelepah kelapa sawit merupakan jenis limbah padat yang dihasilkan sepanjang tahun oleh perkebunan kelapa sawit [6], merupakan sumber biomassa terbesar yang tersedia di perkebunan [10]. Pelepah kelapa sawit termasuk kategori limbah basah (wet by-products) karena masih mengandung kadar air sekitar 70-75\% [12]. Jumlah produksi pelepah kelapa sawit sekitar $5500 \mathrm{~kg} /$ (ha) (tahun) [4].
Unsur kimiawi yang terdapat pada pelepah kelapa sawit berupa selulosa, lignin, dan hemiselulosa menyebabkan pelepah kelapa sawit dapat digunakan sebagai bahan alternatif untuk membuat karbon aktif. Komposisi kimia serat pelepah kelapa sawit ditunjukkan pada tabel 1 [12].

Penelitian pemanfaatan limbah perkebunan kelapa sawit menjadi produk yang memiliki nilai ekonomis pada saat ini masih terbatas, misalnya pada pemanfaatan selulosanya digunakan 
sebagai bahan baku pembuatan pulp, pembuatan karbon aktif dari bahan baku cangkang dan tandan kosong kelapa sawit sedangkan dari pelepah sawit, diolah menjadi pakan ternak tetapi masih sebatas penelitian [8]. Unsur kimiawi yang terdapat pada pelepah kelapa sawit berupa selulosa, lignin, dan hemiselulosa menyebabkan pelepah kelapa sawit dapat digunakan sebagai bahan alternatif untuk membuat karbon aktif [1]. Komponenkomponen yang terdapat pada serat pelepah kelapa sawit ditunjukkan pada Tabel 1.

Tabel 1. Komponen dan Komposisi Senyawa Penyusun Pelepah Kelapa Sawit

\begin{tabular}{|l|c|}
\hline \multicolumn{1}{|c|}{$\begin{array}{c}\text { Komponen } \\
\text { Kimia }\end{array}$} & Kandungan (\%) \\
\hline Lignin & $16,77 \pm 0,30$ \\
\hline Selulosa & $36,33 \pm 4,10$ \\
\hline Hemiselulosa & $30,34 \pm 4,54$ \\
\hline $\begin{array}{l}\text { Komponen kimia } \\
\text { lain }\end{array}$ & 6,66 \\
\hline
\end{tabular}

Karbon aktif adalah karbon padat atau serbuk dengan luas permukaan yang besar yang dihasilkan dengan cara pirolisis menggunakan metode aktivasi fisika atau kimia [5]. Karbon aktif banyak dimanfaatkan oleh berbagai bidang industri untuk berbagai tujuan, diantaranya pemurnian gas, pembersih air, pengolahan limbah cair, mengadsorpsi bau, warna, gas serta logam [9]. Pada penelitian ini akan dianalisa perbandingan morfologi dan gugus fungsi dari karbon aktif dengan aktivator asam fosfat dan asam nitrat.

\section{Teori}

Pelepah sawit atau oil palm frond (OPF) sangat besar, jumlahnya hampir sama dengan produksi tandan buah segarnya seperti terlihat pada Tabel $2[12,15]$.

Tabel 2. Ketersediaan Limbah Padat Pelepah Kelapa Sawit tahun 2011-2016.

\begin{tabular}{|c|c|c|}
\hline Tahun & $\begin{array}{c}\text { Luas Perkebuan } \\
\text { (ha) }\end{array}$ & $\begin{array}{c}\text { Pelepah } \\
\text { (Ton) }\end{array}$ \\
\hline 2011 & 8.992 .824 & 14.748 .231 \\
\hline 2012 & 9.572 .715 & 15.699 .252 \\
\hline 2013 & 10.465 .020 & 17.162 .632 \\
\hline 2014 & 10.754 .801 & 17.637 .873 \\
\hline 2015 & 11.300 .370 & 185.326 .068 \\
\hline 2016 & 11.672 .861 & 191.434 .920 \\
\hline
\end{tabular}

Karbon aktif memiliki luas permukaan yang besar dan daya adsorpsi yang tinggi sehingga pemanfaatannya dapat optimal. Karbon aktif yang baik harus memiliki luas permukaan yang besar sehingga daya adsorpsinya juga besar [2].

Secara umum proses pembuatan karbon aktif terdiri dari tiga tahapan yaitu dehidrasi, aktivasi dan karbonisasi [2]. Dehidrasi adalah proses penghilangan kandungan air yang terdapat dalam bahan baku karbon aktif dengan tujuan untuk menyempurnakan proses karbonisasi [3]. Karbonisasi adalah proses pembakaran material organik pada bahan baku yang menyebabkan terjadinya dekomposisi material organik bahan baku dan pengeluaran pengotor [16]. Aktivasi adalah proses pengaktifan karbon yang bertujuan untuk membuka pori-pori, memperbesar luas permukaan dan meningkatkan porositas yaitu dengan cara memecahkan ikatan hidrokarbon atau mengoksidasi molekul-molekul permukaan sehingga karbon mengalami perubahan sifat baik fisika maupun kimia yaitu luas permukaannya bertambah besar sifat baik fisik maupun kimia yaitu luas permukaannya bertambah besar dan berpengaruh terhadap daya adsorpsi [7].

Kualitas karbon aktif tergantung dari jenis bahan baku, teknologi pengolahan, cara pengerjaan dan ketepatan penggunaannya. Indonesia telah membuat pula standar mutu karbon aktif menurut standar industri Indonesia yaitu SII 0258-79 yang kemudian direvisi menjadi SNI 06-3730-1995 [14] seperti terlihat pada Tabel 3 .

Tabel 3. Standar Kualitas Karbon Aktif

\begin{tabular}{|l|c|c|c|}
\hline \multirow{2}{*}{ Uraian } & Satua & \multicolumn{2}{|c|}{ Persyaratan } \\
\cline { 3 - 4 } & nutiran & Serbuk \\
\hline $\begin{array}{l}\text { Bagian yang } \\
\text { hilang pada } \\
\text { pemanasan } \\
950^{\circ} \mathrm{C}\end{array}$ & $\%$ & Maks.15 & $\begin{array}{c}\text { Maks. } \\
25\end{array}$ \\
\hline Kandungan air & $\%$ & $\begin{array}{c}\text { Maks. } \\
4,5\end{array}$ & $\begin{array}{c}\text { Maks. } \\
15\end{array}$ \\
\hline Kandungan abu & $\%$ & $\begin{array}{c}\text { Maks. } \\
2,5\end{array}$ & $\begin{array}{c}\text { Maks. } \\
10\end{array}$ \\
\hline $\begin{array}{l}\text { Bagian yang } \\
\text { tidak terkarbon }\end{array}$ & - & 0 & 0 \\
\hline $\begin{array}{l}\text { Daya serap I } 2 \\
\text { Karbon aktif } \\
\text { murni (Fixed } \\
\text { carbon) }\end{array}$ & $\%$ & Min. 750 & $\begin{array}{c}\text { Min. } \\
750\end{array}$ \\
\hline
\end{tabular}

\section{Metodologi Penelitian}

Pelepah kelapa sawit lolos ayakan 32 mesh sebanyak 30 gram diaktivasi dengan aktivator asam fosfat dan asam nitrat dengan konsentrasi $20 \%$, selama 2 jam pada suhu $80{ }^{\circ} \mathrm{C}$ lalu diimpregnasi selama 24 jam pada suhu ruangan. Kemudian disaring untuk memisahkan filtrat dan 
larutan. Sampel dikarbonisasi menggunakan furnace pada suhu $400{ }^{\circ} \mathrm{C}$ selama 1 jam. Kemudian dicuci hingga $\mathrm{pH}$ netral dengan air destilat pada suhu $85^{\circ} \mathrm{C}$. Kemudian dipanaskan di dalam oven pada suhu $110{ }^{\circ} \mathrm{C}$ selama 2 jam untuk proses pengeringan karbon aktif.

\section{Hasil}

Analisis Morfologi Permukaan Karbon Aktif

Analisa morfologi permukaan karbon aktif dikarakterisasi menggunakan SEM pada masingmasing aktivator. Hasil yang diperoleh dari hasil analisis SEM ditunjukkan pada Gambar 1.

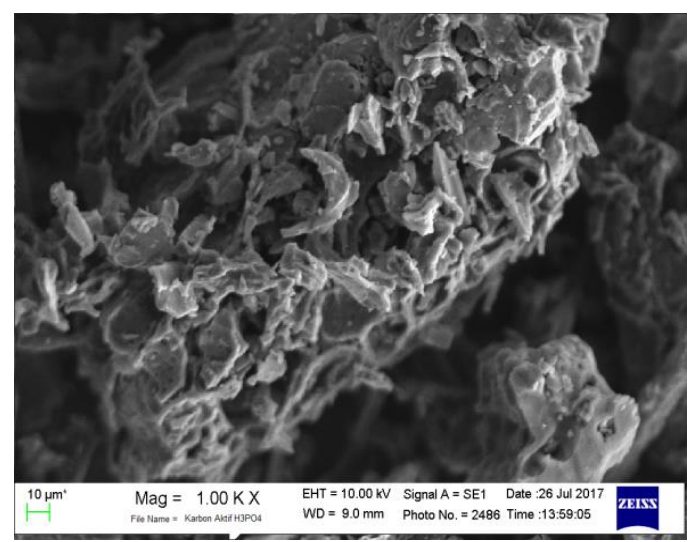

(a)

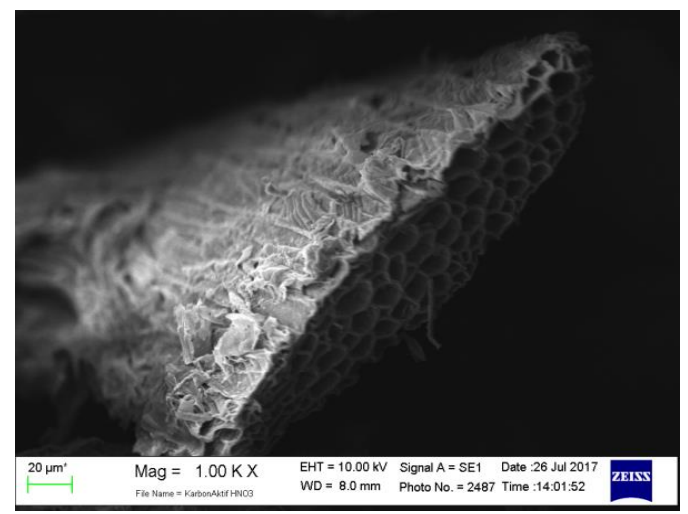

(b)

Gambar 1. Hasil Analisis Morfologi Menggunakan SEM (a) Karbon Aktif Teraktivasi Asam Fosfat (b) Karbon Aktif Teraktivasi Asam Nitrat

Pada gambar 1 dapat dilihat morfologi permukaan karbon aktif dari pelepah kelapa sawit memiliki permukaan pori-pori yang kasar dan tidak teratur. Pembentukan dan pembesaran pori disebabkan oleh penguapan komponen selulosa yang terdegradasi dan lepasnya zat terbang. Pengurangan senyawa hidrokarbon menghasilkan permukaan karbon aktif terlihat semakin jelas. Proses aktivasi bertujuan untuk memperbesar pori yaitu dengan cara memecahkan ikatan hidrokarbon atau mengoksidasi molekul-molekul permukaan sehingga karbon mengalami perubahan yaitu luas permukaannya bertambah besar dan berpengaruh terhadap daya adsorpsi. Struktur pori-pori yang terbentuk berasal dari penguapan dan pelarutan senyawa-senyawa non-karbon yang terdapat di dalam bahan baku yang disebabkan oleh proses pirolisis, yang bisa meninggalkan beberapa ruang kosong yang membentuk pori-pori [13].

Pada gambar di atas terdapat perbedaan struktur pori karbon aktift eraktivasi asam fosfat dengan karbon aktif teraktivasi asam nitrat. Pada karbon aktif teraktivasi asam fosfat, pori-pori yang terbentuk lebih banyak dan membentuk rongga pori-pori dengan kedalaman yang lebih besar dan merata serta kontur permukaan yang lebih kasar dan tidak teratur bila dibandingkan dengan karbon aktif teraktivasi asam nitrat.

\section{Analisis Gugus Fungsi Karbon Aktif}

Analisa gugus fungsi karbon aktif yang diperoleh dapat dianalisa dengan metode Fourier Transform Infrared (FTIR), yaitu metode spektroskopi inframerah yang dilengkapi dengan transformasi Fourier untuk analisis hasil spektrumnya. Metode spektroskopi yang digunakan adalah metode absorpsi, yaitu metode spektroskopi yang didasarkan atas perbedaan penyerapan radiasi inframerah. Hasil yang diperoleh dari hasil analisis FTIR ditunjukkan pada Gambar 2.

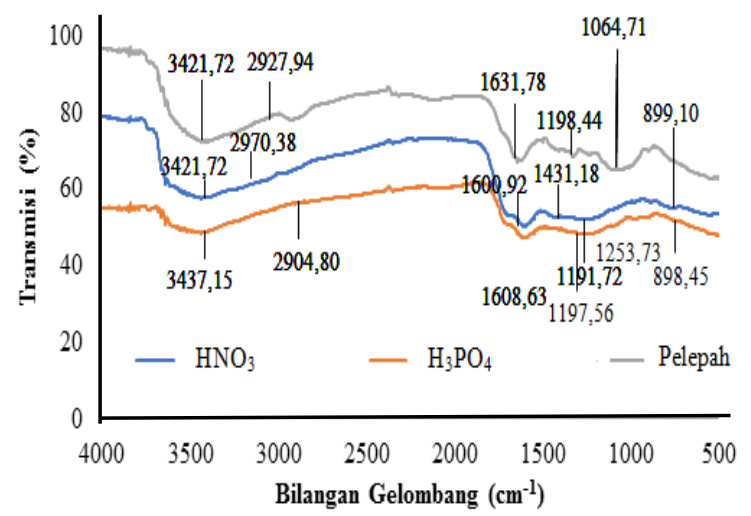

Gambar 2. Hasil Fourier Transform Infra Red (FTIR) Pelepah Kelapa Sawit, Karbon Aktif Asam Fosfat dan Karbon Aktif Asam Nitrat

Puncak serapan $3734,19 \mathrm{~cm}^{-1}$ dimiliki oleh pelepah kelapa sawit, karbon aktif asam nitrat dan karbon aktif asam fosfat. Puncak serapan pada bilangan $3500-3200 \mathrm{~cm}^{-1}$ (merujuk pada $\mathrm{O}-\mathrm{H}$ stretching) mengindikasi adanya gugus fungsi O-H (hidroksil). Dari hasil yang diperoleh terjadi penurunan puncak serapan, hal ini terjadi karena penguraian gugus hidroksil dan air yang teradsorpsi. Besarnya 
gugus hidroksil menunjukkan adanya ikatan hidrogen yang kuat (dari karboksil, fenol atau alkohol).

Penurunan puncak serapan merupakan petunjuk mulai terbentuknya senyawa aromatik yang merupakan unsur penyusun karbon aktif [10]. Pada spectrum gelombang FTIR karbon aktif asam nitrat dan asam fosfat, muncul puncak serapan dengan bilangan gelombang $1600,92 \mathrm{~cm}^{-}$ ${ }^{1}$ dan $1608,63 \mathrm{~cm}^{-1}$. Puncak serapan pada bilangan $1820-1600 \mathrm{~cm}^{-1}$ mengindikasikan keberadaan gugus $\mathrm{C}=\mathrm{O}$. Gugus $\mathrm{C}=\mathrm{O}$ merupakan gugus khas yang terdapat pada karbon aktif dan menunjukkan bahwa pelepah kelapa sawit membentuk zat aktif karbon [11].

Pada karbon aktif teraktivasi asam fosfat menunjukkan bahwa terbentuk bilangan gelombang pada rentang $900-1200 \mathrm{~cm}^{-1}$, hal tersebut dikarenakan adanya penyerapan oleh $\mathrm{OH}, \mathrm{CH}, \mathrm{C}-\mathrm{OH}$ dan $\mathrm{CH}_{2}$ pada unit glikosil dalam karbon aktif [10]. Karbon aktif yang dihasilkan memiliki pola serapan dengan jenis ikatan $\mathrm{OH}$, $\mathrm{C}=\mathrm{O}$, dan $\mathrm{C}-\mathrm{O}$. Adanya ikatan $\mathrm{OH}$ dan $\mathrm{C}-\mathrm{O}$ menunjukkan bahwa karbon aktif yang dihasilkan cenderung bersifat lebih polar. Dengan demikian karbon aktif yang dihasilkan dapat digunakan sebagai adsorben zat yang cenderung polar seperti untuk penjernihan air, gula, alkohol atau sebagai penyerap emisi formaldehid [11].

Proses aktivasi pada karbon aktif asam nitrat telah membentuk ikatan $\mathrm{C}=\mathrm{C}$ yang ditandai dengan adanya pemunculan spectrum pada bilangan gelombang 1431,18 $\mathrm{cm}^{-1}$. Puncak serapan pada bilangan 1500-1400 $\mathrm{cm}^{-1}$ mengindikasikan keberadaan gugus $\mathrm{C}=\mathrm{C}$. Gugus $\mathrm{C}=\mathrm{C}$ menunjukkan adanya peningkatan kadar karbon.

Karbon aktif teraktivasi asam nitrat membentuk ikatan amina yang ditandai dengan adanya spektrum pada bilangan gelombang $1253,73 \mathrm{~cm}^{-1}$ mengindikasikan keberadaan gugus C-N (1350-1000 $\mathrm{cm}^{-1}$ ) [11]. Pada puncak serapan $1431,18 \mathrm{~cm}^{-1}$ dimiliki oleh karbon aktif teraktivasi asam nitrat hal ini mengindikasikan keberadaan gugus $\mathrm{N}=\mathrm{O}\left(1550-1350 \mathrm{~cm}^{-1}\right)$ yang menunjukkan adanya gugus nitro. Sedangkan pada puncak serapan dengan bilangan gelombang 2970,38 $\mathrm{cm}^{-1}$ dan 2904,60 $\mathrm{cm}^{-1}$ mengindikasikan keberadaan gugus $\mathrm{C}-\mathrm{H}$ (3000$2850 \mathrm{~cm}^{-1}$ ) yang menunjukkan adanya senyawa alkana [11]. Gugus fungsi yang terdapat pada karbon aktif pelepah kelapa sawit yaitu gugus

Phanerochaete chrysosporium dan Trametes Versicolor, Jurnal Penelitian Hasil Hutan, 32 (2) (2014): hal 111-122.
$\mathrm{C}=\mathrm{O}, \mathrm{C}=\mathrm{C}, \mathrm{C}-\mathrm{C}, \mathrm{N}=\mathrm{O}, \mathrm{C}-\mathrm{N}, \mathrm{C}-\mathrm{OH}, \mathrm{CH}_{2}$ dan $\mathrm{C}-$ H.

\section{Kesimpulan}

Hasil yang diperoleh pada penelitian ini mengenai analisa morfologi dan gugus fungsi pada karbon aktif diperoleh pada morfologi permukaan karbon aktif teraktivasi asam fosfat pori-pori yang terbentuk lebih banyak dan membentuk rongga-rongga pori dengan kedalaman yang lebih besar bila dibandingkan dengan karbon aktif teraktivasi asam nitrat.

Hasil identifikasi dengan spektrofotometer FTIR menunjukkan bahwa karbon aktif pada penelitian ini mengandung gugus fungsi $\mathrm{C}=\mathrm{O}$, $\mathrm{C}=\mathrm{C}, \mathrm{C}-\mathrm{C}, \mathrm{N}=\mathrm{O}, \mathrm{C}-\mathrm{N}, \mathrm{C}-\mathrm{OH}, \mathrm{CH}_{2}$ dan $\mathrm{C}-\mathrm{H}$.

\section{Daftar Pustaka}

[1] Allwar, R. Winarsi, N. Fitriyani, K. Merdekawati, Characterization and Application of Activated Carbon from Oil Palm Shell Prepared by Pyhisical Activation and Nitric Acid for the Removal of Phenol and 2-Chlorophenol, International Journal of Science and Research (IJSR) ISSN : 2319-7064, (2015).

[2] Bansal dan R. Chand, Activated Carbon Adsorption, Taylor \& Francis Group, Boca Raton London New York, Singapore, LLC.

[3] B.H Hameed, K. Y. Foo, Porous Structure and Adsorptive Properties of Pineapple Peel Based Activated Carbons Prepared Via Microwave Assisted $\mathrm{KOH}$ and $\mathrm{K}_{2} \mathrm{CO}_{3}$ Activation, Malaysia : School of Chemical Engineering, Engineering campus, University Sains Malaysia, 2011.

[4] Dahlan, Oil Palm Frond a Feed for Herbivores, Asian-Australian Journal Animal. University Putra Malaysia, (2000) C(3) : 300-303.

[5] D. Kalderis, S. Bethanis, et al, Production of Activated Carbon From Bagasse And Rice Husk by a Single-Stage Chemical Activation Method at Low Retention Times, Bioresource Technology (2008) 99(15) : 6809-6816.

[6] E. Hermiati, L. Risanto, S. H. Anita, Y. Aristiawan, Y. Sudiyani, A. Hanafi, H. Abimanyu, Sakarifikasi Serat Tandan Kosong dan Pelepah Kelapa Sawit Setelah Pretreatment Menggunakan Kultur Campuran Jamur Pelapuk Putih

[7] J. S. Aznar, Characterization of Activated Carbon Produced from Coffe Residues by Chemical and Physical Activation, KTH Chemical Science and Engineering, Stockholm, Sweden, 2011. 
[8] K. Simanihuruk, Junjungan, S.P Ginting, Pemanfaatan Silase Pelepah Kelapa Sawit Sebagai Pakan Basal Kambing Kacang Fase Pertumbuhan (Utilization Of Oil Palm Frond Silages As Basal Diet For Kacang Goats In Growth Phase), Badan Pusat Statistik Indonesia. Bps Jakarta Indonesia, 2008.

[9] L. Mody, W. Syafii dan G. Pari, Sifat Mutu Arang Aktif Tempurung Kelapa, Jurnal Penelitian Hasil Hutan, 2012, Vol. 30(2) : 100-113.

[10] Mohideen, M. Faizal, M. Faiz, H. Salleh, H. Zakaria, R. V. Raghavan, Drying of Oil Palm Frond via Swirling Fluidization Technique. Proceedings of the World Congress on Engineering, (2011) Vol III. ISSN : 2078-0966.

[11] Pavia, L. Donald, M Gary, S. Lampman, George, Kriz, Introduction to Spectroscopy Aguide for Students of Organic Chemistry, Third Edition, Western Washington University hal. 26.

[12] Salman, Optimization of Preparation Conditions for Activated Carbon From Oil Palm Frond Using Response Surface Methodology on Removal of Pesticides from Aqeous Solution, Arabian Journal Chemsitry, (2014), 7 (3), 101-108.

[13] S.M Yakout, G. Sharaf El-Deen, Characterization of Activated Carbon Prepared by Phosphoric Acid Activation of Olive Stones, Arabian Journal of Chemistry 9, (2016), S1155-S1162.

[14] Standar Nasional Indonesia, Arang aktif Teknis (SNI 06-3730-1995), Jakarta : Badan Standarisasi Nasional Indonesia, 1995.

[15] United States Department of Agriculture, Oilseeds and Products Annual Report. 2016.

[16] X. Wang, D. Li, J. Peng, H. Xia, L. Zhang, S. Guo, G. Zhen, Optimization of Mesoporous Activated Carbon from Coconut Shells by Chemical Activation With Phosporic Acid. Bioresouces (2013) 8 (4), 6184-6195. 